\title{
What Sir Luke Fildes' 1887 painting The Doctor can teach us about the practice of medicine today
}

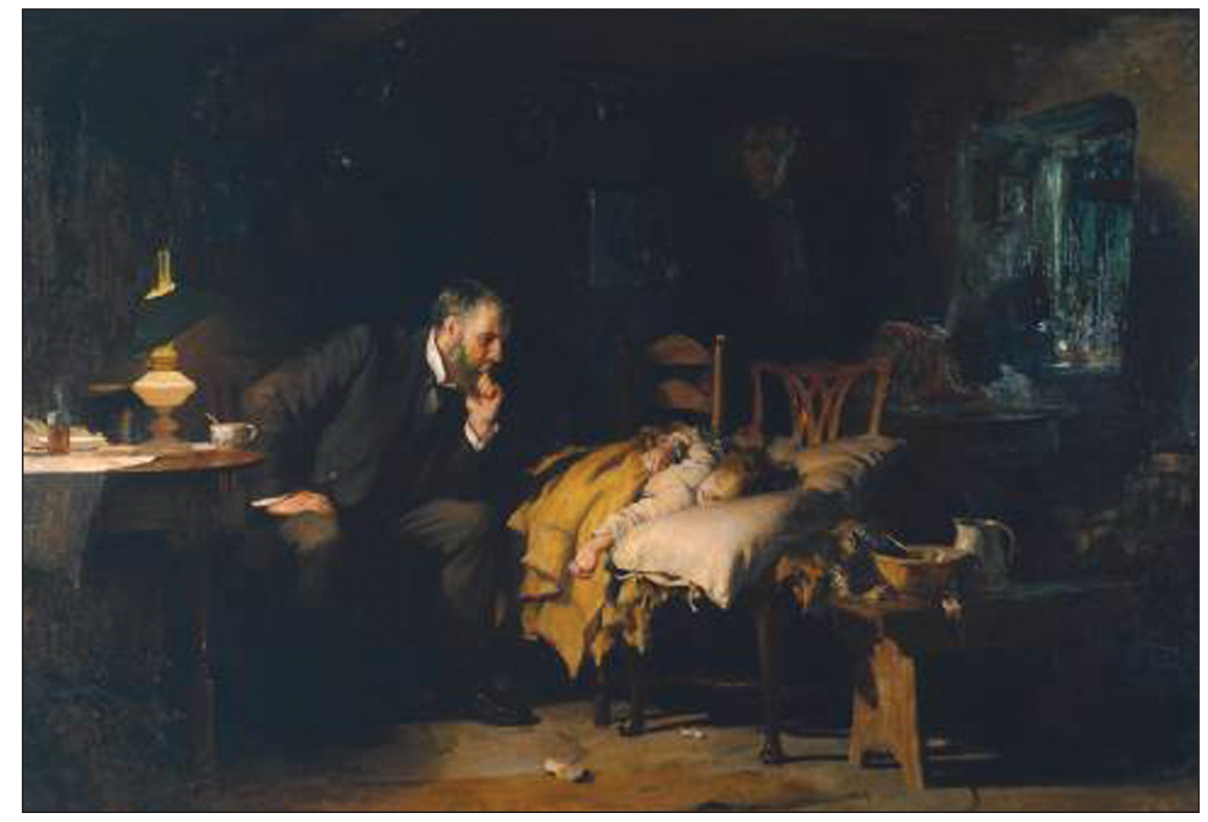

Sir Luke Fildes: The Doctor 1887, Oil on canvas, 1664 × 2419 mm frame: 2075 x 2855 x 210 mm. The Tate Britain, London.

Sir Luke Fildes' painting The Doctor (1887, The Tate Britain, London) is the enduring image of the Victorian GP and is frequently used to portray the qualities of a good doctor to this day. This image of the ideal, dedicated doctor has appeared in many and different settings and can be found in almost any context in our contemporary culture when considering the qualities or shortcomings of the medical profession. This article looks at the context of Fildes' painting and asks if it is an accurate representation of historical reality. This leads to a consideration of the status and attributes of a doctor in contemporary society and what we may learn about this from a study of Fildes' painting.

Fildes' celebrated 1887 work, The Doctor, depicts a Victorian GP on a home visit. He is watching over an impoverished labourer's sick child; the bed is makeshift, two nonmatching chairs pushed together; the cottage interior humble, befitting the labourer's status. The central figure is the imposing male doctor, gazing intently at his patient, while in the background the father looks on helplessly his hand on the shoulders of his tearful wife. The doctor is observing the 'crisis' of the child's illness, the critical stage in pre-antibiotic days when the patient is no longer overwhelmed by infection. The breaking light of dawn on the child's face suggests the crisis is over and that recovery is possible. Fildes' skilful use of light and perspective focuses the eye on the doctor, the patient, and the relationship between them. The child's parents are peripheral, almost irrelevant, the father is watchful but disempowered by the presence of the expert, and the mother, in a stereotypically female role, is collapsed but accepting succour from the hand of the more powerful male. 'The doctor broods, and in truth there was very little more he could do; he was almost as helpless as the parent only 6 feet and three or four social classes away', writes Douglas. ${ }^{1}$
As the effectiveness of medicine in the mid-19th century was limited, the doctor's contribution was unlikely to have had any influence on the recovery of the child, and Douglas continues:

'So his manner is all, and Fildes captures it forever: the furrowed brow; the hand propping the firm bearded chin; the calm, concerned authority'.

The picture received much praise from contemporary critics and was received positively by this doctor writing in the British Medical Journal in 1892:

'What do we not owe to Mr Fildes for showing the world the typical doctor, as we would like to be shown - an honest man and a gentleman, doing his best to relieve suffering? A library of books in our honour would not do what this picture has done and will do for the medical profession in making the hearts of our fellow man warm to us with confidence and affection. ${ }^{2}$

Sir Luke Fildes (1843-1927) was a wellknown Victorian painter of the social realist movement. He was a contemporary of Charles Dickens, the author and campaigner for social reform, and provided the illustrations for Dickens' last novel The Mystery of Edwin Drood (1870). Fildes was aware of the power of pictorial imagery to project a message, having worked on The Graphic newspaper. This illustrated weekly magazine, established in 1869, published images of poverty and injustice with the aim of galvanising acts of charity and collective social action. Although in his early career Fildes made his name by painting works depicting the plight of the poor, like other painters of his era, most of his income came from painting portraits for wealthy clientele 
including Sir Cecil Rhodes and several members of the royal family. The Doctor was painted on commission from the industrialist Sir Henry Tate, for £3000, then a vast sum of money, and was offered by Tate as a gift to the nation in 1897 shortly before the opening of the Tate Gallery in London. ${ }^{3}$

Different stories exist about the origins of the painting. It may have been inspired by the death of Fildes' eldest son, Phillip, who died on Christmas morning 1877, attended by a Dr Murray, who impressed Fildes with the care and attention he gave to his dying child. Another version has Queen Victoria ordering the painting to commemorate the service of her own physician, Sir James Clark, who she was said to have sent to care for the sick child of a servant on the Balmoral estate. It is known that the picture was painted in Fildes' London studio where he had carefully constructed a cottage interior and the 'doctor' was a professional model but thought to bear some resemblance to Fildes himself. Therefore, this picture, although based on a real event in the artist's experience, was as fictional and romantic an account of a doctor's activity as that found in novels of the period which include George Elliot's Dr Lydgate in Middlemarch (1871) or even Mary Shelley's Dr Frankenstein (Frankenstein, 1818).

Fildes' The Doctor may have been contrived as a reaction to general societal concerns about the increase in scientific medicine in the late 18th and early 19th centuries. Until the 18th century physicians based a large part of their diagnosis on what their patients told them and physical examination was limited, involving little more that pulse taking and minute examination of the excreta, exquisitely portrayed in the 1994 film version of Alan Bennett's play, The Madness of King George. Observation and prognostication which had been the basis of western medicine throughout the middleages was challenged by Enlightenment thinking as new theories based on rational scientific enquiry developed.

The subsequent rapid and varied pace of medical developments gave rise to an optimism that man had the potential to understand and conquer disease but also led to a sense of unease. This was apparent in the Romantic Movement, a literary and artistic reaction to the rationality of Enlightenment philosophers and scientists such as Descartes, Locke, and Newton. Instead, the Romantics celebrated the beauty of unspoilt nature and asserted the value of individual liberty and personal experience. The potential dangers of scientific intervention was the theme of Mary Shelley's ghost story Frankenstein, a version of the myth of Prometheus, which explored the consequences of defying the laws of God and nature. This book gave society the dramatic image of a misguided $\mathrm{Dr}$ Frankenstein whose disastrous attempt to harness the potential of electricity as a metaphor for suspicion concerning scientific development.

Although GPs were widely established in every area of Britain by the start of the 19th century, they could do little to overcome the consequences of rural poverty or the degradation and squalor of urban life resulting from the social change and population shifts of the Industrial Revolution. Surgical developments had been rapid as a result of improvements in pain control and anaesthesia throughout the 19th century, * but were undermined by lack of hygiene. A visit to the old Operating Theatre at Guy's Hospital London is a powerful evocation of the time, and shows how a surgeon before operating would don a coat stiff with the dried blood and discharges of previous patients, the badge of honour for a busy surgeon showing how popular his work was. Although pain had not prevented surgery in the past, it had made it almost unbearable as described in a valuable primary source, the dairies of Fanny Burney. ${ }^{4}$ The account of her mastectomy without anaesthetic in 1810, a macabre ritual endured by a woman at the hand of her male executioner, was as ghastly and gothic as any fiction.

The use of anaesthesia developed rapidly from Davy's first experiments with 'laughing gas' at the beginning of 19th century to become fairly normal practice in some hospitals just 50 years later. When $\mathrm{Dr}$ John Snow (better known in the context of the

*Since antiquity attempts had been made to deaden surgical pain or induce a trance-like state with the use of alcohol, opium, and mandrake root (as used to induce Juiet's coma in Romeo and Juliet, William Shakespeare, 1595) but more effective methods awaited developments in chemical methods from the late 18 th to the early 19 th centuries.
Broad Street Pump) administered chloroform to Queen Victoria for the birth of Prince Leopold in 1853, she recorded in her journal that 'the effect was soothing, quieting and delightful beyond measure.' Protests followed, some on religious grounds, as the Bible taught that women were to bring forth in pain, but other objections were medical, on safety grounds. The Lancet responded cautiously: 'In no case can it be justifiable to administer chloroform in perfectly normal labour'. ${ }^{5}$ This may be an illustration that the general public was more ready to accept medical advances than the establishment and a rather reactionary medical profession.

The medical implications of another invention of the Victorian age that invoked suspicion was the use of the telephone, patented by Alexander Graham Bell in 1876. In a fascinating parallel with the present day, Fildes' painting was cited in an article edited in the Lancet in 1887, which criticised diagnosis and therapy by telephone, an issue still causing controversy today. ${ }^{6}$ The article comments on the picture:

'The child lies desperately ill while the parents huddle in the background, fearful, helpless, and grief-stricken. There is nothing more the physician can do medically to save the child. Why, then, is he still there? He can only keep vigil-watching as the girl's delicate breath grows ever more shallow. Now picture a different scene - one with the physician's chair empty, and the two distraught parents clutching a phone receiver."

This same comment could be written today as telephone consulting is used increasingly and is widely endorsed by the government which set up NHS Direct in 1997 to offer 24-hour telephone advice. The limitations of such a service have been criticised in the media recently following the public enquiry into the death of a 41-year-old journalist in 2005 from septicaemia and multiple organ failure who had accessed NHS Direct on eight separate occasions in the days before her death. ${ }^{7}$

Fildes' painting shows a Victorian family doctor on a home visit. However, a consideration of the role of the family doctor 
at that time would make it seem unlikely that a doctor would make such a visit, let alone spend an overnight vigil in those circumstances. The Victorian family doctor, the trusted friend and confidant, provided a service for the rapidly expanding middleclasses, writes Hogarth, ${ }^{8}$ who adds:

\section{'... as long as medical treatment has been a commodity to be bought and sold, the quality of treatment has varied according to the social status of patients.'}

The account of the activities of a family doctor in Anthony Trollope's Dr Thorne (1858) endorses this view. The novel includes great detail of $\mathrm{Dr}$ Thorne's involvement in the financial, social, and medical affairs of his wealthy patients but only occasionally mentions brief visits to the less affluent. Trollope himself wrote:

\section{'A novel should give a picture of common life ... to make that picture worthy of attention the canvas should be crowded with real portraits ... impregnated with traits of the characters which are known."}

From this it can be assumed that $D r$ Thorne, though a work of fiction providing a secondary historical source, presents a plausible description of general practice at the time.

A look at the detail in Fildes' painting shows us some of the paraphernalia used by the doctor in his vigil. There is a pestle and mortar and a cup and a spoon suggesting he may have made a potion or poultice to apply to the sick child, but no evidence of the equipment commonly used at the time the picture was painted, such as a stethoscope or a thermometer. It is likely that a doctor by this time would have adopted the practices of bio-medicine which required measurable, quantitative evidence rather than relying on qualitative observation and judgement. Even George Elliott's $\mathrm{Dr}$ Lydgate uses a stethoscope in Middlemarch published in 1871. Porter writes that a more scientific approach was 'lapped up' by patients who appreciated the rituals of scientific, diagnostic medicine. 'It gave them the impression of commanding the doctor's attention when he used his stethoscope or sphygmomanometer, when he rapped and tapped and listened'. ${ }^{5}$ As a result, 'no longer was there a need to spend lengthy vigils with a patient, instead, through the use of the latest technology the well-respected GPs could impress upon patients that they were skilful, serious, attentive, upright: they knew what they were doing and could be trusted'. ${ }^{6}$

Fildes himself stated that his ambition and motivation for the choice of subject of The Doctor was 'to put on record the status of the doctor in our own time. ${ }^{10}$ However, as this study's exploration of the painting's historical context suggests, it was far from being an accurate representation of historical reality and a more realistic portrayal would be very different. This picture of a doctor as 'a hero in the service of humanity' working on a 'mission of mercy' in surroundings of abject poverty not only enhanced the image of the caring doctor, but also the status of the medical professional and the establishment as a whole,by suggesting they had the power to confront the difficulties encountered by society. ${ }^{11}$ Fildes' contrived and fictionalised image may have been conceived to influence Victorian public opinion and was, in fact, a fine example of Victorian spin! ${ }^{12}$

Fildes' portrayal of the qualities of a good doctor in his painting The Doctor is neither realistic nor historically accurate, but it endures to the present day. Can it still teach us anything? The Healing Arts, an illustrated anthology edited by Downie, ${ }^{13}$ includes a print of the picture and this endorsement:

\section{'This painting is an eloquent portrayal of what medicine is all about - the doctor, the patient, and the quality of the relationship that exists between them. The physician is attending the patient, watching and waiting - being there. Much of the painting's impact is the space between the physician's eyes and the child, which is filled, solely, by the patient's gaze. ${ }^{13}$}

In fact the essence of Fildes' picture The Doctor is the depiction of the quality of 'patient-centredness', an essential feature of the contemporary doctor-patient relationship and an important consideration for all doctors.

In the mid-to-late 19th century, when The Doctor was painted, medicine was in transition and the increasing predominance of the scientific medical model was sidelining the patient's narrative to focus on the opinion of the 'expert', the doctor. Jewson describes this change as the reconceptualisation of the 'sick man' who becomes 'the accident of his disease' as new medical ideologies increased the objectivity of medical assessments but gave no consideration of the subjective viewpoint of the patient. ${ }^{14}$ Foucault, in The Birth of the Clinic, ${ }^{15}$ also considers this line of thinking and describes this shift in emphasis as a change in orientation of the 'medical gaze'.

As the patient was sidelined by the change in 'medical gaze', the doctor, the 'expert', became more powerful and medicine moved from the bedside to the hospital. Yet up to the time of the Medical Act in 1858 only one doctor in three had any formal or recognisable qualifications. By setting compulsory standards for academic and clinical training this act raised the standing of all doctors, and was of particular significance for GPs formerly in the shadow of physicians and surgeons attached to hospitals. The GP was now not only the family doctor and specialist in primary care, but also the gatekeeper controlling access to the hospital and the specialist. The Medical Act also created the General Medical Council, an ethico-legal watchdog with jurisdiction over malpractice and 'infamous conduct', and established the first Medical Register, a unified list of 15000 approved medical practitioners (this figure is around 200000 today). ${ }^{16}$

Fildes' The Doctor was painted at a time of great social change; industrialisation of the workplace was resulting in huge population shifts with ensuing urban poverty and rural neglect. Despite this, there remained relative societal stability and certainty and a clear social hierarchy existed between experts and lay people, patients and doctors. Dramatic medical advances continued throughout the late 19th to the 20th century, from the discovery of antibiotics to the first organ transplants. However, despite these advances, the role and power of the medical professions began to be challenged. By the 1970s, the late-modern period, optimism in medical progress was replaced by disillusionment and doubt as medical costs soared with little apparent benefit. The NHS was established in 1948 with the aspiration of 
providing health care for all of society, but instead health inequalities appeared to be widening between social classes for both men and women and for different ethnic groups. ${ }^{17}$ It was also demonstrated that many important diseases responsible for mortality rates up to the time of the establishment of the NHS had disappeared before the relevant medical innovations had occurred, and were the result of higher living standards, improved diet, and improved public health and hygiene.

Late modern society, critical of technological solutions, developed an increasing awareness of the uncertainties and contingent nature of medical and scientific knowledge; the more science and technology intruded in people's lives, the more it was questioned. Non-professional 'experts' or lay people questioned medical and scientific knowledge rather than accepting it uncritically and doctors were subject to increased scrutiny as patients became more engaged in monitoring their own health. The information revolution gave people access to complex and possibly conflicting sources of advice and information and they started to make their own decisions without recourse to the 'expert'.

One of the most damning indictments of modern medicine was Ivan Illich's Limits to Medicine: Medical Nemesis published in $1976 .{ }^{18}$ Illich argued that analysis of current patterns of mortality showed modern medicine was not only ineffective but caused positive damage and had become counterproductive. While it had originally brought some benefit, he claimed that 'in striving unrealistically to chase the goal of immortality' high technology medicine had created a modern nemesis (Nemesis: the Greek god of retribution and vengeance) that made it a positive threat to health. Although Illich's arguments now seem flawed and his solution (the empowerment of the layman to make his own decisions in not just the personal but at all levels of health policy) unrealistic, he was not the only critic. Freidson ${ }^{19}$ felt that doctors had misused the legitimate authority that came from their knowledge and expertise by establishing a self-interested, provider-dominated healthcare system.

In our contemporary culture of media scrutiny and accountability, there are numerous accounts of medical negligence and newly-exposed shortcomings of the medical profession, and as a result doctors no longer seem respected or to be regarded as figures of authority. It is apparent that patients have moved from absolute faith in doctors' decisions to question the treatment they are having, something many doctors find uncomfortable. However, it is not just the medical profession that is under pressure; in our post-modern society all authority is questioned by the layman who has concerns about identity, sex, politics, and the relativism of 'truth'. Society is expressing what Eric Hobsbawm ${ }^{20}$ calls 'libertarian individualism', which by putting a greater emphasis on individual needs and desires is less accepting of 'truth by authority'.

Doctors have always been held in high regard in society, and our perception may be that our predecessors were held in higher esteem in public opinion than we are today. However, criticism of the medical profession is an age-old tradition: 'doctors have been revered, derided, lionized and occasionally massacred, as happened in the Middle Ages when they failed to conquer the Black Death'. ${ }^{21}$ 'Once medicine proved effective, the scourge of pestilence was forgotten, and the physician no longer had to be thanked and could be disparaged as a figure of authority, a tool of patriarchy or a stooge of the state. ${ }^{21}$ An 1856 Times editorial compared doctors favourably with the greed of parsons and the ruthless avarice of lawyers and commended doctors for their consideration of their patients' best interests. ${ }^{22}$ Contemporary surveys show that doctors are still one of the most respected professional groups, regularly topping the list of most trusted professions, and certainly trusted more than politicians, journalists, or lawyers. ${ }^{23}$ It may be that the medical profession has not, as yet, realised that the change in how they are perceived represents a wider change in societal attitudes and a better understanding of this may allow them to deal with their patients' expectations more effectively.

Although a more detailed appraisal of Fildes' 1887 painting The Doctor shows that it was a contrived and improbable portrayal of medicine even at the time it was painted, it can still teach us an important lesson about the practice of medicine today. Fildes uses his skills as an artist to engage and involve us in the image he portrays and encourages us to explore our own medical practice. Fildes' artistry makes us look at what is important in the picture; the relationship between the patient and the doctor. Most importantly, Fildes' timeless painting The Doctor reminds contemporary doctors of the crucial importance of the relationship between a patient and the doctor and the value of a patient-centred approach.

\section{Jane Moore}

\section{REFERENCES}

1. Douglas C. Doing better, looking worse. BMJ 2002; 325: 720

2. W Mitchell Banks. Doctors in literature. BMJ 1892; 8 787-788.

3. Wilson S. The Tate Gallery, an illustrated companion to the national collections of British \& modern art. Tate Gallery Publications: Millbank, London, 1990.

4. Burney F. Journals and letters. London: Penguin Classics, 2001.

5. Porter R. The greatest benefit to mankind: a medical history of humanity from antiquity to the present. London: Fontana, 1997.

6. Aronson SH. The Lancet on the telephone 1876-1975. Med Hist 1977; 21(1): 69-87.

7. Nigel Hawkes. The Times. Failings in out-of-hours GP care 'will claim more victims'. http://www.timesonline.co.uk/tol/ news/uk/health/article1843039.ece (accessed 1 Feb 2008).

8. Hogarth $\mathrm{S}$, Marks L. The golden narrative in British medicine. In Greenhalgh T, Hurwitz B (eds). Narrative based medicine: dialogue and discourse in clinical practice. London: BMJ Books, 1998: 142

9. Rendell R. Introduction to Dr Thorne (first published 1858). London: Penguin Books, 2004.

10. Wilson S. Tate Gallery: an illustrated companion. Millbank: Tate Gallery Publications, 1990.

11. Nochlin L. Realism. London: Penguin Books, 1971.

12. Borsay A. The Doctor — an interlude.' Swansea, University of Wales: MA Medical Humanities Course, 2005.

13. Downie RS. The healing arts. Oxford: Oxford University Press, 1994.

14. Jewson ND. The disappearance of the sick man from medical cosmology. Sociology 1976; 10: 225-244.

15. Foucault M. The birth of the clinic. London: Routledge Classics, 1973.

16. The Medical Register. General Medical Council: London, http://www.gmc-uk.org/register (accessed 29 Jan 2008).

17. Graham H. Understanding health inequalities. Buckingham, London: Oxford University Press, 2000.

18. Illich I. Limits to medicine: medical nemesis - the expropriation of health. London: Marion Boyars, 1976.

19. Friedson E. The profession of medicine: a study of the sociology of applied knowledge. New York: Dodd, Mead, 1970.

20. Hobsbawm E. The new century. London: Little, Brown, 2000.

21. Camp J. The healers art. New York: Taplinger Publishing Co., 1977.

22. Thomas Stuttaford. The Times. Brought forth in pain and sorrow. http://www.timesonline.co.uk/tol/life_and_style/ health/features/article1882303.ece (accessed 1 Feb 2008).

23. MORI poll. Opinion of professions. Ipsos Mori: London, 2005. http://www.ipsos-mori.com/trust/truth.shtml (accessed 29 Jan 2008)

DOI: 10.3399/bjgp08X279571 